\title{
Leptin is Associated with Local Stiffness of the Carotid Artery in Overweight Patients with Type 2 Diabetes
}

Ryutaro Numaguchi' ${ }^{1}$, Tomoaki Morioka ${ }^{1 *}$, Yuko Yamazaki ${ }^{1}$, Satoshi Imamura ${ }^{1}$, Hiromi Urata ${ }^{1}$, Koka Motoyama ${ }^{1}$, Katsuhito Mori', Shinya Fukumoto $^{2}$, Tetsuo Shoji ${ }^{3}$, Masanori Emoto ${ }^{1}$ and Masaaki Inaba ${ }^{1}$

${ }^{1}$ Department of Metabolism, Endocrinology and Molecular Medicine, Osaka City University, Graduate School of Medicine, Osaka, Japan

${ }^{2}$ Department of Premier Preventive Medicine, Osaka City University Graduate School of Medicine, Osaka, Japan

${ }^{3}$ Department of Geriatrics and Vascular Medicine, Osaka City University Graduate School of Medicine, Osaka, Japan

\begin{abstract}
Objective: Besides its major role in the regulation of food intake and energy expenditure, leptin is involved in the pathogenesis of obesity-associated atherosclerosis. However, the clinical association between leptin and arterial stiffness, a surrogate marker for cardiovascular disease, has not been fully elucidated. This study aimed to investigate the association between the plasma leptin level and arterial stiffness in patients with type 2 diabetes.

Methods: Three hundred eighteen patients with type 2 diabetes, of which 155 were overweight (body mass index $\geq 25 \mathrm{~kg} / \mathrm{m}^{2}$ ), were included in this study. Fasting plasma leptin levels were measured by enzyme-linked immunosorbent assay. Stiffness of the common carotid artery was evaluated by ultrasonography using Peterson's elastic modulus (Ep) and arterial compliance (AC). Aortic stiffness was assessed by measuring the pulse wave velocity (PWV) in the heart-femoral segment.

Results: The mean age, duration of diabetes, and body mass index of the subjects were 60 years, 6 years, and $25.4 \mathrm{~kg} / \mathrm{m}^{2}$, respectively. Plasma leptin levels were higher in the overweight group than in the lean group (median, 5.8 vs. $2.4 \mathrm{ng} / \mathrm{mL}$ ). Multiple regression analyses adjusted by age, sex, body mass index, and other cardiovascular risk factors revealed that the plasma leptin level was independently associated with carotid Ep and AC in the overweight group, but not in the lean group. The plasma leptin level was not independently associated with aortic PWV in either group.

Conclusion: The plasma leptin level is associated with carotid arterial stiffness in overweight type 2 diabetes patients, independently of obesity and traditional cardiovascular risk factors. This study indicates an unfavorable effect of leptin on carotid arterial stiffness in diabetes with obesity.
\end{abstract}

Keywords: Leptin; Overweight; Type 2 diabetes; Carotid artery; Arterial stiffness; Arterial compliance; Pulse wave velocity; Cardiovascular disease

Abbreviations: BMI: Body Mass Index; ARB/ACEI: Angiotensin-II Receptor Antagonists or Angiotensin Converting Enzyme Inhibitors; BP: Blood Pressure; HbA1c: Glycated Hemoglobin Alc; HOMA-R: Homeostatic Model Assessment of Insulin Resistance; HDL: Highdensity Lipoprotein; LDL: Low-density Lipoprotein; Ep: Peterson's Elastic Modulus; AC: Arterial Compliance; PWV: Pulse Wave Velocity

\section{Introduction}

Obesity is a major factor contributing to the development of atherosclerotic cardiovascular diseases (CVDs), independently or in combination with co-existing risk factors such as hypertension, dyslipidemia, insulin resistance, and type 2 diabetes (T2D) [1-3]. Aortic stiffness, as evaluated by measuring the aortic pulse wave velocity (PWV), is not only associated with aging and various CVD risk factors but also has an independent predictive value for CVDs in the general population, elderly subjects, and patients with hypertension, T2D, and end-stage renal disease [4,5]. Additionally, several studies have indicated that carotid arterial stiffness, which can be evaluated non-invasively by ultrasonography, is associated with the risk of CVD [6-9] and mortality $[10,11]$, although the results are not consistent $[4,12]$. Previous studies involving a large number of subjects showed that obesity or visceral adiposity is independently associated with increased aortic [13-16] and carotid [17-20] stiffness. However, pathophysiological mechanisms linking visceral obesity to arterial stiffening are not fully understood, although insulin resistance and increased levels of circulating leptin and proinflammatory cytokines have been proposed [3].

Recent studies have shown that, besides its major role in energy metabolism, leptin is involved in the pathogenesis of atherosclerosis, including vascular cell proliferation and dysfunction, inflammation, thrombosis, and calcification, and have suggested that an increased plasma leptin level contributes to atherosclerotic CVDs in obese subjects $[1,21]$. The predictive value of the plasma leptin level for coronary artery disease has been demonstrated in population-based studies $[22,23]$. Several studies have investigated the clinical impact of leptin on vascular morphology and function. The plasma leptin level was associated with intima-media thickness (IMT) of the carotid artery in healthy subjects [24] and in psoriasis patients [25], but not significantly in other studies in the community individuals [26] and

*Corresponding author: Tomoaki Morioka, Department of Metabolism Endocrinology and Molecular Medicine, Osaka City University, Graduate School of Medicine, 1-4-3 Asahi-machi, Abeno-ku, Osaka, 545-8585 Japan, Tel: +81-6-66453806; Fax: +81-6-6645-3808; E-mail: m-tomo@med.osaka-cu.ac.jp

Received November 05, 2015; Accepted November 24, 2015; Published November 28, 2015

Citation: Numaguchi R, Morioka T, Yamazaki Y, Imamura S, Urata H, et al. (2015) Leptin is Associated with Local Stiffness of the Carotid Artery in Overweight Patients with Type 2 Diabetes. J Diabetes Metab 6: 627. doi:10.4172/2155-6156.1000627

Copyright: (c) 2015 Numaguchi R, et al. This is an open-access article distributed under the terms of the Creative Commons Attribution License, which permits unrestricted use, distribution, and reproduction in any medium, provided the original author and source are credited. 
in diabetic patients $[27,28]$, possibly due to population variability. Our research group previously reported that plasma leptin levels were associated with carotid IMT in patients with T2D receiving insulin therapy, independent of obesity and other CVD risk factors [29].

Regarding arterial stiffness, several studies have shown that plasma leptin is positively associated with aortic PWV in the general population $[30,31]$ and in patients with nonalcoholic fatty liver disease [32], but not significantly in patients with T2D [14,33]. The plasma leptin level was also independently associated with arterial compliance as measured by the Finometer in obese hypertensive women [34]. On the other hand, limited studies are available on the relationship between leptin and elastic properties of local arteries measured by ultrasonography $[27,35]$, which showed the association of serum leptin with elastic function of the brachial artery [35] or the common carotid artery [27] in adolescents.

Previous studies, including our own [36-38], have consistently shown that diabetic individuals have greater stiffness of the aorta $[39,40]$ and the carotid artery $[36,38,41,42]$ than non-diabetic controls. However, to date, no study has examined the association between leptin and arterial stiffness by simultaneously evaluating vascular stiffness of the aorta and local arteries in patients with T2D. Therefore, in this cross-sectional study, we investigated the association of the plasma leptin level with local stiffness of the carotid artery and aortic PWV in T2D patients.

\section{Materials and Methods}

\section{Subjects}

We consecutively enrolled 318 subjects with T2D, including 190 men and 128 women, who were admitted to the Diabetes Center of the Osaka City University Hospital between March 2005 and August 2012. T2D was diagnosed based on the criteria of the American Diabetes Association [43]. Subjects with type 1 diabetes, other types of diabetes, or renal impairment with a serum creatinine level $\geq 1.1 \mathrm{mg} / \mathrm{dL}$, which is the upper limit of the normal range in our laboratory, were excluded from this study. T2D patients treated with insulin were also excluded from this study. Smokers were defined as current or past smokers in our analyses. Subjects were divided into the lean (body mass index (BMI) $\left.<25 \mathrm{~kg} / \mathrm{m}^{2}\right)$ or the overweight $\left(\mathrm{BMI} \geq 25 \mathrm{~kg} / \mathrm{m}^{2}\right)$ group for analyses. All subjects provided written informed consent, and the ethical review board of our institution approved the study protocol (No. 164).

\section{Physical and laboratory analyses}

Blood pressure (BP) was determined using the conventional cuff method with an automatic sphygmomanometer after the subject had rested for at least $15 \mathrm{~min}$. Blood was drawn after an overnight fast and biochemical parameters were analyzed using a standard laboratory method as described previously [29]. Plasma leptin levels were measured with a commercial enzyme-linked immunosorbent assay kit (R \& D Systems, Inc., Minneapolis, MN) as described previously $[29,44]$.

\section{Measurements of arterial stiffness}

Carotid arterial stiffness was assessed by measuring the distension of the common carotid artery using an ultrasonic phase-locked echo-tracking system equipped with a high-resolution real-time 13$\mathrm{MHz}$ linear scanner (ProSound SSD 6500, Hitachi Aloka Medical, Ltd., Tokyo, Japan) as reported previously $[36,38,45]$. In brief, a $\sim 4-$ $\mathrm{cm}$ region of the common carotid artery was scanned bilaterally in longitudinal and transverse projections. The image was focused on the far wall of the artery. Peterson's elastic modulus (Ep), an index of arterial wall stiffness, was calculated as $(\mathrm{Ps}-\mathrm{Pd}) /[(\mathrm{Ds}-\mathrm{Dd}) / \mathrm{Dd}]$ $(\mathrm{kPa})$, where Ps and Pd are the systolic and diastolic BP, respectively, and Ds and Dd are the systolic and diastolic inner diameters of the artery,respectively. Arterial compliance (AC), which is an index of elasticity and therefore inversely related to stiffness, was calculated as $\pi(\mathrm{Ds} \times \mathrm{Ds}-\mathrm{Dd} \times \mathrm{Dd}) /[4(\mathrm{Ps}-\mathrm{Pd})](\mathrm{mm} 2 / \mathrm{kPa})$. Ep is the pressure change required for a (theoretical) $100 \%$ increase in diameter, and AC is the absolute change in diameter with pressure [4]. A high Ep value and low AC value were used as markers of advanced carotid stiffness.

Aortic stiffness was evaluated by measuring PWV in the heartfemoral segment using an automatic waveform analyzer (Model BP203RPE; Omron Colin Co., Ltd., Tokyo, Japan) as described previously $[39,46]$. Reproducibility of the measurement of arterial stiffness was confirmed in our previous reports, in which the coefficients of variation were less than $5 \%$ for both carotid stiffness [36] and heartfemoral PWV [39].

\section{Statistical analysis}

Data are expressed as the number (\%), mean \pm standard deviation (SD), or median (interquartile range) as appropriate. For comparisons between the lean and overweight groups, $\chi 2$ - test, Student's $t$-test, or Wilcoxon rank-sum test was used as appropriate. Skewed parameters, such as immunoreactive insulin, insulin resistance index by homeostasis model assessment (HOMA-R), triglycerides, and leptin were logarithmically transformed before regression analysis. In multiple regression analysis, carotid Ep, carotid AC, or aortic PWV was the dependent variable, and the following were independent variables: age, sex, BMI, systolic BP, creatinine level, glycated hemoglobin Alc (HbAlc) level, log [HOMA-R], high-density lipoprotein (HDL)cholesterol level, low-density lipoprotein (LDL)-cholesterol level, smoking status, presence of treatment with statins, and presence of angiotensin-II receptor blocker (ARB) or angiotensin- converting enzyme inhibitors (ACEIs). A p-value $<0.05$ was considered significant. Statistical analyses were performed using the $\mathrm{JMP}^{\circledR} 10$ software (SAS Institute Inc., Cary, NC, USA).

\section{Results}

\section{Clinical characteristics of the subjects}

Table 1 shows the clinical characteristics of the total population as well as of lean and overweight subjects separately. Ninetytwo subjects $(29 \%)$ were treated with dietary therapy alone, 143 (45\%) with sulfonylureas, $86(27 \%)$ with biguanides, 56 (18\%) with a-glucosidase inhibitors, 37 (12\%) with thiazolidinediones, 24 (8\%) with dipeptidyl peptidase-4 inhibitors, 14 (4\%) with insulin secretagogues (glinides), and 9 (3\%) with glucagon-like peptide-1 analogs. Clinical characteristics were compared between the lean and overweight groups by $\chi 2$-test, Student's $t$-test, or Wilcoxon rank-sum test as appropriate. Overweight subjects were significantly younger $(p$ $<0.001)$ and had a shorter duration of diabetes $(p=0.001)$ than lean subjects. As expected, overweight subjects had higher diastolic BP ( $p$ $<0.001)$, immunoreactive insulin $(p<0.001)$, HOMA-R $(p<0.001)$, and uric acid levels $(p<0.001)$ and lower HDL-cholesterol levels $(p$ $=0.015)$ than lean subjects. No significant differences were found in the prevalence of smokers ( $p=0.172)$, ARB/ACEI users $(p=0.793)$, or statin users $(p=0.258)$ between the groups.

\section{Plasma leptin levels and arterial stiffness in T2D subjects}

The median plasma leptin level for all subjects was $3.6 \mathrm{ng} / \mathrm{mL}$ (range, 
Citation: Numaguchi R, Morioka T, Yamazaki Y, Imamura S, Urata H, et al. (2015) Leptin is Associated with Local Stiffness of the Carotid Artery in Overweight Patients with Type 2 Diabetes. J Diabetes Metab 6: 627. doi:10.4172/2155-6156.1000627

Page 3 of 7

\begin{tabular}{|c|c|c|c|c|c|}
\hline & & All & Lean & Overweight & $p$-value \\
\hline $\mathrm{N}$ & (male/female) & $318(190 / 128)$ & $163(100 / 63)$ & $155(90 / 65)$ & 0.550 \\
\hline Age & (years) & $60 \pm 12$ & $64 \pm 9$ & $57 \pm 14$ & $<0.001$ \\
\hline Duration of diabetes & (years) & $6(2-12)$ & $8(2-15)$ & $5(1-10)$ & 0.001 \\
\hline BMI & $\left(\mathrm{kg} / \mathrm{m}^{2}\right)$ & $25.4 \pm 4.9$ & $22.1 \pm 2.1$ & $29.0 \pm 4.5$ & $<0.001$ \\
\hline Smoker & $\mathrm{n}(\%)$ & $154(49.4)$ & $85(53.1)$ & $69(45.4)$ & 0.172 \\
\hline ARB/ACEI & $\mathrm{n}(\%)$ & $110(36.1)$ & $57(36.8)$ & $53(35.3)$ & 0.793 \\
\hline Statin & $\mathrm{n}(\%)$ & $106(34.9)$ & $49(31.8)$ & $57(38.0)$ & 0.258 \\
\hline Systolic BP & $(\mathrm{mmHg})$ & $128 \pm 18$ & $127 \pm 19$ & $128 \pm 17$ & 0.875 \\
\hline Diastolic BP & $(\mathrm{mmHg})$ & $74 \pm 10$ & $72 \pm 10$ & $76 \pm 10$ & $<0.001$ \\
\hline Fasting glucose & $(\mathrm{mg} / \mathrm{dL})$ & $129 \pm 34$ & $132 \pm 34$ & $126 \pm 35$ & 0.168 \\
\hline $\mathrm{HbA1c}$ & $\%$ & $8.2 \pm 1.6$ & $8.3 \pm 1.6$ & $8.1 \pm 1.5$ & 0.309 \\
\hline Immunoreactive insulin & $(\mu \mathrm{U} / \mathrm{mL})$ & $6.3(4.3-9.3)$ & $5.1(3.2-7.0)$ & $8.4(6.0-12.1)$ & $<0.001$ \\
\hline HOMA-R & & $2.0(1.3-2.9)$ & $1.6(1.0-2.2)$ & $2.4(1.9-3.7)$ & $<0.001$ \\
\hline Triglycerides & $(\mathrm{mg} / \mathrm{dL})$ & $117(92-156)$ & $113(89-160)$ & $120(96-156)$ & 0.218 \\
\hline HDL-cholesterol & $(\mathrm{mg} / \mathrm{dL})$ & $44 \pm 11$ & $46 \pm 11$ & $43 \pm 10$ & 0.015 \\
\hline LDL-cholesterol & $(\mathrm{mg} / \mathrm{dL})$ & $115 \pm 34$ & $118 \pm 34$ & $113 \pm 35$ & 0.148 \\
\hline Creatinine & $(\mathrm{mg} / \mathrm{dL})$ & $0.73 \pm 0.17$ & $0.72 \pm 0.16$ & $0.74 \pm 0.18$ & 0.388 \\
\hline Uric acid & $(\mathrm{mg} / \mathrm{dL})$ & $5.8 \pm 1.4$ & $5.4 \pm 1.3$ & $6.1 \pm 1.4$ & $<0.001$ \\
\hline Leptin & (ng/mL) & $3.6(1.9-6.8)$ & $2.4(1.3-4.1)$ & $5.8(3.3-9.3)$ & $<0.001$ \\
\hline Carotid Ep & $(\mathrm{kPa})$ & $177 \pm 97$ & $170 \pm 82$ & $183 \pm 110$ & 0.259 \\
\hline Carotid AC & $\left(\mathrm{mm}^{2} / \mathrm{kPa}\right)$ & $0.58 \pm 0.26$ & $0.58 \pm 0.25$ & $0.58 \pm 0.27$ & 0.830 \\
\hline Aortic PWV & $(\mathrm{cm} / \mathrm{s})$ & $1064 \pm 249$ & $1122 \pm 247$ & $1002 \pm 237$ & $<0.001$ \\
\hline
\end{tabular}

Data are expressed as the mean $\pm \mathrm{SD}$, median (interquartile), or $\mathrm{n}(\%)$ as appropriate. $P$-values from Student's $t$-test, Wilcoxon rank-sum test, or $\mathrm{X}^{2}$-test, overweight group vs. lean group. BMI, body mass index; smoker, prevalence of current or past smokers; ARB/ACEI, prevalence of subjects treated with angiotensin-II receptor antagonists or ACE inhibitors; statin, prevalence of subjects treated with statins; BP, blood pressure; HbA1c, glycated hemoglobin A1c; HOMA-R, homeostatic model assessment of insulin resistance; HDL, high-density lipoprotein; LDL, low-density lipoprotein; Ep, Peterson's elastic modulus; AC, arterial compliance; PWV, pulse wave velocity.

Table 1: Clinical characteristics, plasma leptin levels, and arterial stiffness in all, lean, and overweight subjects with type 2 diabetes

(a)

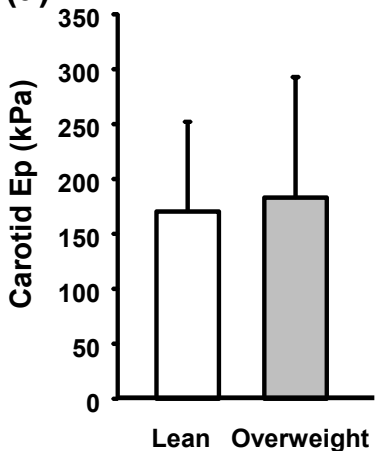

(b)

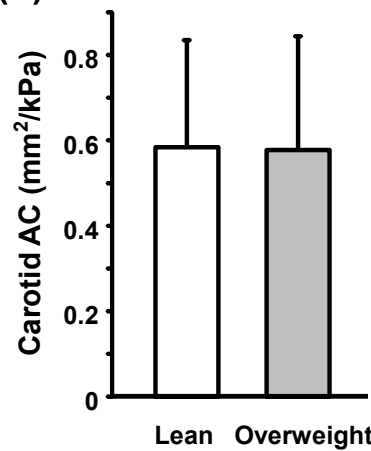

(c)

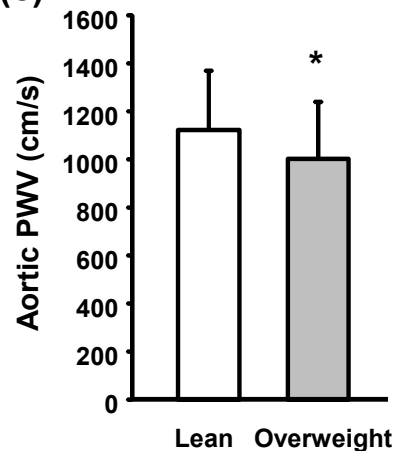

Figure 1: Comparison of (a) carotid Ep, (b) carotid AC, or (C) aortic PWV between the lean and the overweight groups. *, $p<0.001$ vs. the lean group by Student's- $t$ test.

$0.2-64.2 \mathrm{ng} / \mathrm{mL})$. As expected, plasma leptin levels in the overweight group were higher than those in the lean group $(p<0.001$ by Wilcoxon rank-sum test) (Table 1). The mean values of carotid Ep and AC for the total population were $177 \mathrm{kPa}$ (range, $45-960 \mathrm{kPa}$ ) and $0.58 \mathrm{~mm}^{2} / \mathrm{kPa}$ (range, $0.1-2.0 \mathrm{~mm}^{2} / \mathrm{kPa}$ ), respectively. No significant difference was found in carotid Ep or AC between the lean and the overweight groups ( $p=0.259$ or 0.830 by Student's $t$-test). The mean value of aortic PWV for the total population was $1064 \mathrm{~cm} / \mathrm{s}$ (range, $483-1931 \mathrm{~cm} / \mathrm{s}$ ), and the overweight subjects had significantly lower PWV than the lean subjects $(p<0.001$ by Student's $t$-test) (Table 1 and Figure 1$)$

\section{Association between plasma leptin levels and arterial stiffness}

We first examined the association of the plasma leptin level with carotid Ep, AC, or aortic PWV by simple linear regression analyses for the total population and then for the lean and the overweight groups, separately. Neither carotid Ep nor AC was significantly correlated with the plasma leptin level in the total population (Ep, $r=0.041, p=0.488$; AC, $r=-0.069, p=0.241$ ), the lean group (Ep, $r=0.038, p=0.648$; AC, $r=-0.097, p=0.243$ ), or the overweight group (Ep, $r=-0.008, p=$ 0.925 ; AC, $r=-0.049, p=0.558$ ) (Figure 2 ). Aortic PWV was negatively correlated with plasma leptin in the total population $(r=-0.205, p<$ $0.001)$ and the overweight group $(r=-0.170, p=0.040)$, but not in the lean group $(r=-0.049, p=0.550)$ (Figure 2$)$.

To identify an independent association between plasma leptin and arterial stiffness, we next performed multiple regression analyses after adjusting for age, sex, BMI, systolic BP, creatinine, HbA1c, HOMA-R, 
(a)

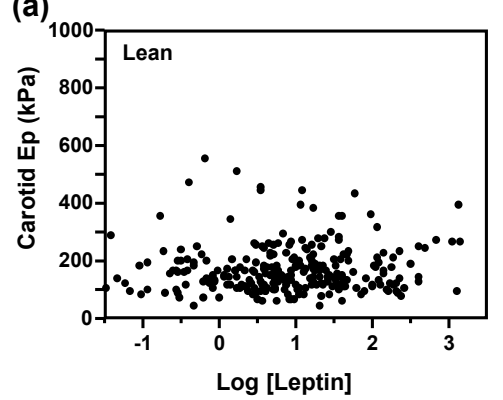

(d)

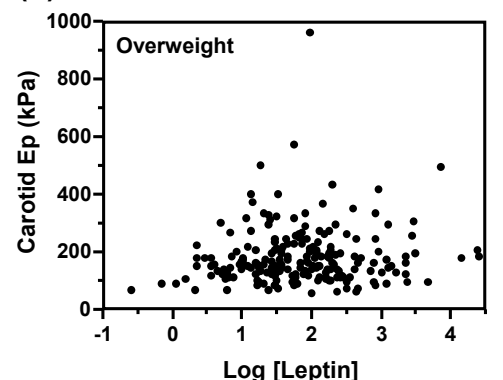

(b)

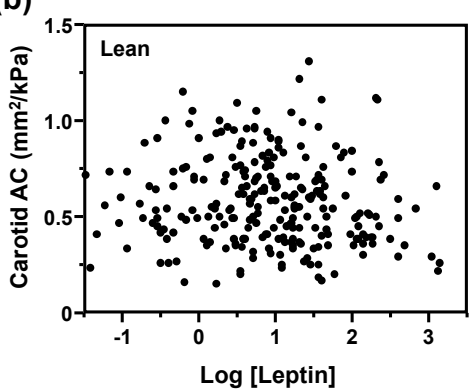

(e)

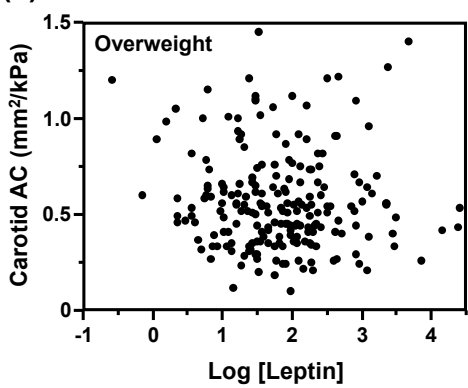

(c)

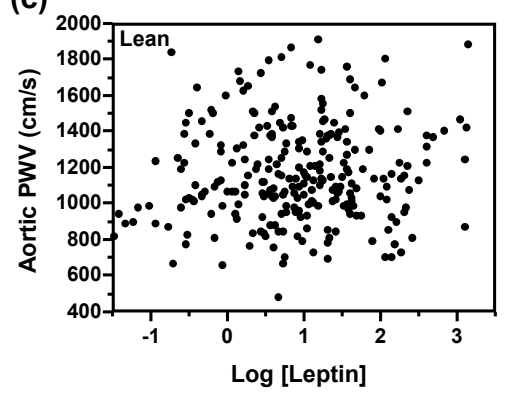

(f)

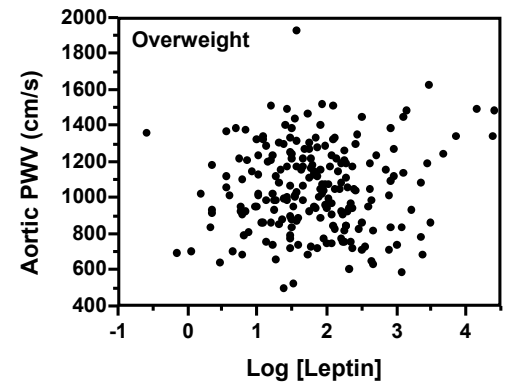

Figure 2: Association of plasma leptin levels with carotid Ep (a,d), carotid AC (b, e), or aortic PWV (c, f) in the lean (a, b, c) or the overweight (d, e, f) group.

\begin{tabular}{|c|c|c|c|c|c|c|}
\hline & \multicolumn{2}{|c|}{ Carotid Ep } & \multicolumn{2}{|c|}{ Carotid AC } & \multicolumn{2}{|c|}{ Aortic PWV } \\
\hline & Lean & Overweight & Lean & Overweight & Lean & Overweight \\
\hline Age (years) & 0.073 & $0.395^{* *}$ & -0.040 & $-0.405^{\star *}$ & $0.432^{* *}$ & $0.453^{* *}$ \\
\hline Sex $($ male $=1)$ & -0.205 & 0.168 & 0.205 & -0.144 & 0.096 & -0.085 \\
\hline $\mathrm{BMI}\left(\mathrm{kg} / \mathrm{m}^{2}\right)$ & 0.067 & -0.009 & 0.144 & 0.176 & 0.093 & $-0.197^{*}$ \\
\hline Systolic BP (mmHg) & $0.548^{* *}$ & $0.299^{* *}$ & $-0.388^{* *}$ & $-0.207^{\star \star}$ & $0.343^{* *}$ & $0.375^{\star *}$ \\
\hline Creatinine $(\mathrm{mg} / \mathrm{dL})$ & $0.187^{*}$ & 0.117 & -0.063 & -0.006 & -0.036 & 0.060 \\
\hline $\mathrm{HbA} 1 \mathrm{c}(\%)$ & -0.062 & $0.191^{*}$ & 0.042 & $-0.197^{\star \star}$ & 0.027 & 0.085 \\
\hline Log [HOMA-R] & $0.210^{*}$ & -0.144 & -0.217 & 0.076 & 0.034 & -0.134 \\
\hline HDL-cholesterol (mg/dL) & 0.054 & -0.017 & -0.020 & -0.056 & 0.031 & $-0.153^{*}$ \\
\hline LDL-cholesterol (mg/dL) & 0.140 & -0.068 & -0.162 & 0.030 & 0.037 & 0.036 \\
\hline Smoker $($ yes $=1)$ & 0.023 & 0.070 & -0.017 & 0.029 & 0.111 & 0.108 \\
\hline Statin (yes = 1) & -0.007 & 0.090 & -0.020 & -0.043 & -0.098 & 0.003 \\
\hline ARB/ACEI (yes = 1) & 0.056 & 0.097 & 0.010 & 0.049 & 0.045 & 0.038 \\
\hline Log [leptin (ng/mL)] & -0.188 & $0.241^{*}$ & 0.096 & $-0.293^{\star *}$ & -0.054 & 0.035 \\
\hline $\mathrm{R}^{2}$ & $0.411^{* *}$ & $0.403^{* *}$ & $0.221^{* *}$ & $0.380^{* *}$ & $0.398^{* *}$ & $0.591^{\star *}$ \\
\hline
\end{tabular}

Values are standardized regression coefficients $(\beta)$ determined by multiple regression analysis. $\mathrm{R}^{2}$, coefficient of determination; ${ }^{*}, p<0.05 ;{ }^{*}, p<0.01$. BMI, body mass index; smoker, prevalence of current or past smokers; ARB/ACEI, prevalence of subjects treated with angiotensin-II receptor antagonists or ACE inhibitors; statin, prevalence of subjects treated with statins; BP, blood pressure; HbA1c, glycated hemoglobin A1c; HOMA-R, homeostatic model assessment of insulin resistance; HDL, high-density lipoprotein; LDL, low-density lipoprotein; Ep, Peterson's elastic modulus; AC, arterial compliance; PWV, pulse wave velocity.

Table 2: Multiple regression analyses of the determinants for arterial stiffness in patients with type 2 diabetes.

HDL-cholesterol, LDL-cholesterol, smoking, use of statin, and use of $\mathrm{ARB} / \mathrm{ACEI}$ in the lean and the overweight groups. The plasma leptin level (Ep, $\beta=0.241, p=0.028$; AC, $\beta=-0.293, p=0.009$ ), as well as age (Ep, $\beta=0.395, p<0.001$; AC, $\beta=-0.405, p<0.001)$, systolic BP (Ep, $\beta=$ $0.299, p<0.001 ; \mathrm{AC}, \beta=-0.207, p=0.006)$ and HbAlc $(\mathrm{Ep}, \beta=0.191$, $p=0.010$; AC, $\beta=-0.197, p=0.009)$, was found to be an independent determinant of carotid Ep and $\mathrm{AC}$ in the overweight group, but not in the lean group (Ep, $\beta=-0.188, p=0.175 ; \mathrm{AC}, \beta=0.096, p=0.545$ ) (Table 2). On the other hand, plasma leptin was not independently associated with the aortic PWV in either the lean $(\beta=-0.054, p=0.693)$ or the overweight $(\beta=0.035, p=0.701)$ group (Table 2$)$.

\section{Discussion}

The present study demonstrated that high plasma leptin levels were associated with increased carotid arterial stiffness in overweight T2D patients, but not in lean patients. Of importance, the association was independent of obesity and traditional CVD risk factors. Furthermore, no association was observed between the plasma leptin level and aortic stiffness in our subjects. These findings indicate that leptin plays an important role in promoting local stiffness of the carotid artery in patients with T2D complicated by obesity. This study clearly demonstrated that in overweight, but not in lean patients with T2D, the 
plasma leptin level is a major determinant of carotid arterial stiffness, independently of obesity, insulin resistance, and other CVD risk factors. As expected, plasma leptin levels in the overweight group were markedly higher than those in the lean group, reflecting the increased amount of adipose tissue and elevated hypothalamic leptin resistance $[1,47]$. Experimental studies have suggested that leptin exerts several atherogenic effects such as endothelial dysfunction, inflammation, oxidative stress, thrombosis, and proliferation and migration of vascular smooth muscle cells, and indicates that hyperleptinemia plays an important role in obesity-associated atherosclerotic CVDs $[1,21]$. Moreover, evidence from studies utilizing animal models of obesity suggests selective leptin resistance; only the satiety and weightreducing effects of leptin are impaired, whereas its other actions, including atherogenic effects on blood vessels, are preserved in obese individuals $[1,21,48]$. Collectively, these findings indicate that leptin might directly act on the vascular wall to impair arterial elasticity and compliance in overweight T2D subjects in which the circulating level of leptin is markedly elevated.

The clinical relationship between obesity or abdominal adiposity and local arterial stiffness measured by ultrasonography has been reported in a number of studies in the general population [18-20,49] and in patients with T2D [50,51]. However, only limited reports are available on the relationship between leptin and local arterial stiffness $[27,35]$, which would be important in exploring potential mechanisms underlying the link between obesity and arterial stiffness. Singhal et al. reported that in 294 healthy adolescents between 13 to 16 years of age, high serum leptin levels were associated with impaired distensibility of the brachial artery, and that the association was independent of fat mass, BP, C-reactive protein, fasting insulin, or LDL-cholesterol [35]. Atabek et al. [27] reported that in 45 adolescents with type 1 diabetes (mean age, 14.8 years), high serum leptin levels were unfavorably correlated with compliance, distensibility, and elastic modulus of the common carotid artery, and that these correlations were independent of sex, age, BMI, waist-to-hip ratio, diabetes duration, daily insulin dose, HbAlc, albuminuria, serum lipids, and pubertal stage. As no other reports are available, to our knowledge, this study is the first to associate high plasma leptin levels with local stiffness of the carotid artery in adult patients with diabetes.

As expected from their dominant roles in the pathogenesis of arterial stiffening [4,52], ageing and systolic BP were major determinants of carotid arterial stiffness in overweight T2D patients. Poor glycemic control, possibly through the formation of advanced glycation end-products in diabetic condition [3,52], was also independently associated with carotid stiffness in overweight subjects. Interestingly, only systolic BP was a determinant of carotid stiffness in lean subjects, whereas overweight subjects had multiple factors contributing to carotid stiffness, including age, $\mathrm{BP}, \mathrm{HbAlc}$, and leptin, as indicated in the literatures $[3,52]$. Sex was not a determinant of carotid stiffness in our T2D subjects, as in previous studies in diabetic and non-diabetic subjects $[51,53]$. In contrast, sex was an independent determinant of carotid IMT in the general population $[24,30]$ and in hospitalized subjects with and without T2D [51]. Moreover, in a populationbased study in which carotid IMT and stiffness were simultaneously measured, female sex negatively contributed to carotid IMT, while sex was not significantly associated with carotid stiffness [54]. Collectively, sex difference might have less impact on stiffness than on thickness of the carotid artery.

The plasma leptin level was not significantly associated with aortic PWV in both the lean and overweight groups in our study population.
Several clinical studies have investigated the relationship between plasma leptin and aortic stiffness [14,30-33]. The plasma leptin level was a determinant of aortic PWV, independent of obesity and other confounders, in the general population $[30,31]$ and in patients with nonalcoholic fatty liver disease [32]. In contrast, the leptin level did not independently determine aortic PWV in studies targeting T2D patients [14,33]. Teoh et al. [14] showed that BP, age, waist circumference, diabetes duration, and $\mathrm{HbAlc}$, but not $\mathrm{C}$-reactive protein or adipocytokines including leptin were independently associated with aortic stiffness in older adults (mean age, 69 years; $\mathrm{n}=860$ ) with T2D. Additionally, Satoh et al. [33] demonstrated that not the plasma leptin level alone, but the leptin-to-adiponectin ratio was correlated with aortic PWV in obese (BMI $\geq 25.0 \mathrm{~kg} / \mathrm{m}^{2}$ ) patients with T2D (mean age, 59.8 years, $\mathrm{n}=158$ ). These reports indicated that the impact of leptin on stiffening of the aorta is complicated by various cardiometabolic risk factors and/or dysregulated adipocytokine profile in a diabetic condition.

The different associations of the plasma leptin level with carotid stiffness and aortic PWV in this study could be explained by differences in the arterial sites or segments in which vascular stiffness was assessed. It is well recognized that the elastic properties of arteries are not uniform along the arterial tree; there are substantial differences in properties between central elastic arteries, such as the aorta and the common carotid artery, and peripheral muscular arteries, such as the brachial and the femoral arteries [4]. The Hoorn study demonstrated that the hazard ratios of local carotid stiffness for CVD events and allcause mortality were greater than that of femoral arterial stiffness and carotid-femoral PWV in the general population [55]. Heart-femoral PWV reflects the properties of the mixed elastic and muscular part of the arterial tree $[4,55]$, whereas carotid Ep and AC solely reflect properties of elastic artery; thus, the results of this study indicate that leptin might preferentially affect the functional properties of elastic rather than muscular arteries in individuals with obesity and diabetes. Moreover, in a hospital-based study by Paini et al., the strength of the correlation between carotid arterial stiffness and aortic PWV was weaker in subjects with hypertension and T2D than in those without [56]. Therefore, we speculate that the prevalence of diabetes and obesity caused the different elastic properties observed between the carotid artery and the aorta in this study population.

We previously reported the association between the plasma leptin level and different markers of atherosclerosis in patients with T2D. The plasma leptin level was independently associated with carotid IMT in T2D patients receiving insulin therapy [29]. Leptin and exogenous insulin interact to promote the pathological processes of arterial wall thickness $[1,21]$. Since these processes may also accelerate arterial stiffening, T2D patients receiving insulin therapy were excluded from this study. The study subjects were consequently younger and had shorter duration of diabetes than those in our previous study [29]; therefore, both studies indicate that leptin unfavorably affects arterial elasticity and compliance in overweight patients at an early stage in diabetes-associated atherosclerosis. Further, we recently reported that the plasma leptin level is associated with better endothelial function as evaluated by flow-mediated dilatation of the brachial artery in overweight patients with T2D [44]. Since flow-mediated dilatation reflects short-term bioavailability of endothelial nitric oxide and leptin is known to directly exert a vasodilator effect through endothelial nitric oxide $[1,21]$, the unfavorable effect of leptin on local arterial elasticity and compliance would be independent of nitric oxide-mediated regulation of arterial function. Indeed, a cross-sectional study by the 
Citation: Numaguchi R, Morioka T, Yamazaki Y, Imamura S, Urata H, et al. (2015) Leptin is Associated with Local Stiffness of the Carotid Artery in Overweight Patients with Type 2 Diabetes. J Diabetes Metab 6: 627. doi:10.4172/2155-6156.1000627

Page 6 of 7

other researchers showed that leptin was significantly correlated with distensibility but not with flow-mediated dilatation of the brachial artery in nondiabetic adolescents [35].

This study had several limitations. First, this was a cross-sectional study; therefore, we could not establish a causal relationship between leptin and carotid arterial stiffness. Second, our subjects received antihypertensive drugs and statins, which might have affected arterial stiffness and related atherosclerotic risk factors. To minimize the effect of these treatments, we adjusted for the presence of these therapies in the multiple regression analyses. Third, the overweight subjects were significantly younger than the lean subjects, and possibly therefore had lower aortic PWV than the lean subjects. Since not all potential confounding risk factors could be adjusted for because of the consecutive inclusion of the subjects, we adjusted for factors including age and BMI and confirmed the independent association of leptin in the multivariate analyses. Fourth, our results cannot be generalized because the subjects with T2D were hospitalized largely with inadequate glycemic control. Finally, this study included a small number of morbidly obese subjects with a $B M I \geq 30 \mathrm{~kg} / \mathrm{m}^{2}(\mathrm{n}=37,11.6 \%)$ who would have severe leptin resistance and hyperleptinemia; thus, our results are applicable only to T2D patients with moderate obesity.

This study indicates a potential role of leptin in the pathogenesis of arterial stiffness and proposes the clinical relevance of measuring plasma leptin level in predicting advanced arteriosclerosis, especially in patients with obesity and T2D. Several precedent studies indicate that carotid arterial stiffness can be decreased with weight loss via calorie restriction in obese adults [57] or short-term aerobic exercise without weight loss in T2D patients [45]. Another study further demonstrated that long-term changes in diet and exercise reduced plasma leptin levels, independent of changes in body weight or fat mass, in men with metabolic syndrome [58]. Taken together with our data and prior studies, plasma leptin levels would be one of the potential markers for monitoring the effect of diet or exercise therapy on vascular health in patients with obesity and diabetes.

In conclusion, the present study demonstrates that plasma leptin levels are independently associated with local stiffness of the carotid artery in overweight patients with T2D. Our data indicate that elevated plasma leptin mainly affects carotid arterial stiffness, known as an independent predictor of CVDs, rather than aortic stiffness, in these individuals. Further studies in a population that includes a wide range of BMIs are required to validate these findings. In addition, prospective and interventional studies assessing changes in both plasma leptin levels and arterial stiffness in response to e.g., diet, exercise, or chronic administration of recombinant leptin are warranted to clarify whether plasma leptin levels are predictive of arterial stiffness in patients with obesity and T2D.

\section{Acknowledgements}

The authors acknowledge the excellent technical assistance of Ms. Setsuko Arita and Ms. Mika Sakaki from the research laboratory in the Department of Metabolism, Endocrinology and Molecular Medicine, Osaka City University Graduate School of Medicine.

\section{Funding}

This study was supported by a Grant-in-Aid for Scientific Research (No. 20591068) from the Japan Society for the Promotion of Science (to M.E. and K Mori)

\section{References}

1. Beltowski J (2006) Leptin and atherosclerosis. Atherosclerosis 189: 47-60.

2. Leopold JA (2013) Cellular and molecular mechanisms of arterial stiffness associated with obesity. Hypertension 62: 1003-1004.
3. Safar ME, Czernichow S, Blacher J (2006) Obesity, arterial stiffness, and cardiovascular risk. J Am Soc Nephrol 17: S109-111.

4. Laurent S, Cockcroft J, Van Bortel L, Boutouyrie P, Giannattasio C, et al. (2006) Expert consensus document on arterial stiffness: methodological issues and clinical applications. Eur Heart J 27: 2588-2605.

5. Oliver JJ, Webb DJ (2003) Noninvasive assessment of arterial stiffness and risk of atherosclerotic events. Arterioscler Thromb Vasc Biol 23: 554-566.

6. Dijk JM, Algra A, van der Graaf Y, Grobbee DE, Bots ML, et al. (2005) Carotid stiffness and the risk of new vascular events in patients with manifest cardiovascular disease. The SMART study. Eur Heart J 26: 1213-1220.

7. Leone N, Ducimetiere P, Gariepy J, Courbon D, Tzourio C, et al. (2008) Distension of the carotid artery and risk of coronary events: the three-city study. Arterioscler Thromb Vasc Biol 28: 1392-1397.

8. Mattace-Raso FU, van der Cammen TJ, Hofman A, van Popele NM, Bos ML et al. (2006) Arterial stiffness and risk of coronary heart disease and stroke: the Rotterdam Study. Circulation 113: 657-663.

9. Yang EY, Chambless L, Sharrett AR, Virani SS, Liu X, et al. (2012) Carotid arterial wall characteristics are associated with incident ischemic stroke but not coronary heart disease in the Atherosclerosis Risk in Communities (ARIC) study. Stroke 43: 103-108.

10. Blacher J, Pannier B, Guerin AP, Marchais SJ, Safar ME, et al. (1998) Carotid arterial stiffness as a predictor of cardiovascular and all-cause mortality in endstage renal disease. Hypertension 32: 570-574.

11. Stork S, van den Beld AW, von Schacky C, Angermann CE, Lamberts SW, et al. (2004) Carotid artery plaque burden, stiffness, and mortality risk in elderly men: a prospective, population-based cohort study. Circulation 110: 344-348.

12. van Dijk RA, Dekker JM, Nijpels G, Heine RJ, Bouter LM, et al. (2001) Brachial artery pulse pressure and common carotid artery diameter: mutually independent associations with mortality in subjects with a recent history of impaired glucose tolerance. Eur J Clin Invest 31: 756-763.

13. Sutton-Tyrrell K, Newman A, Simonsick EM, Havlik R, Pahor M, et al. (2001) Aortic stiffness is associated with visceral adiposity in older adults enrolled in the study of health, aging, and body composition. Hypertension 38: 429-433.

14. Teoh WL, Price JF, Williamson RM, Payne RA, Van Look LA, et al. (2013) Metabolic parameters associated with arterial stiffness in older adults with Type 2 diabetes: the Edinburgh Type 2 diabetes study. J Hypertens 31: 1010-1017.

15. Wildman RP, Mackey RH, Bostom A, Thompson T, Sutton-Tyrrell K (2003) Measures of obesity are associated with vascular stiffness in young and older adults. Hypertension 42: 468-473.

16. Wohlfahrt P, Somers VK, Cifkova R, Filipovsky J, Seidlerova J, et al. (2014) Relationship between measures of central and general adiposity with aortic stiffness in the general population. Atherosclerosis 235: 625-631.

17. Ferreira I, Snijder MB, Twisk JW, van Mechelen W, Kemper HC, et al. (2004) Central fat mass versus peripheral fat and lean mass: opposite (adverse versus favorable)associations with arterial stiffness? The Amsterdam Growth and Health Longitudinal Study. J Clin Endocrinol Metab 89: 2632-2639.

18. Snijder MB, Flyvbjerg A, Stehouwer CD, Frystyk J, Henry RM, et al. (2009) Relationship of adiposity with arterial stiffness as mediated by adiponectin in older men and women: the Hoorn Study. Eur J Endocrinol 160: 387-395.

19. Snijder MB, Henry RM, Visser M, Dekker JM, Seidell JC, et al. (2004) Regional body composition as a determinant of arterial stiffness in the elderly: The Hoorn Study. J Hypertens 22: 2339-2347.

20. van Popele NM, Westendorp IC, Bots ML, Reneman RS, Hoeks AP, et al (2000) Variables of the insulin resistance syndrome are associated with reduced arterialdistensibility in healthy non-diabetic middle-aged women Diabetologia 43: 665-672.

21. Dubey L, Hesong Z (2006) Role of leptin in atherogenesis. Exp Clin Cardio 11: 269-275.

22. Soderberg S, Ahren B, Jansson JH, Johnson O, Hallmans G, et al. (1999) Leptin is associated with increased risk of myocardial infarction. J Intern Med 246: $409-418$

23. Wallace AM, McMahon AD, Packard CJ, Kelly A, Shepherd J, et al. (2001) Plasma leptin and the risk of cardiovascular disease in the west of Scotland coronary prevention study (WOSCOPS). Circulation 104: 3052-3056. 
Citation: Numaguchi R, Morioka T, Yamazaki Y, Imamura S, Urata H, et al. (2015) Leptin is Associated with Local Stiffness of the Carotid Artery in Overweight Patients with Type 2 Diabetes. J Diabetes Metab 6: 627. doi:10.4172/2155-6156.1000627

24. Ciccone M, Vettor R, Pannacciulli N, Minenna A, Bellacicco M, et al. (2001) Plasma leptin is independently associated with the intima-media thickness of the common carotid artery. Int J Obes Relat Metab Disord 25: 805-810.

25. Robati RM, Partovi-Kia M, Haghighatkhah HR, Younespour S, Abdollahimajd F (2014) Increased serum leptin and resistin levels and increased carotid intimamedia wall thickness in patients with psoriasis: Is psoriasis associated with atherosclerosis? J Am Acad Dermatol 71: 642-648.

26. Bevan S, Meidtner K, Lorenz M, Sitzer M, Grant PJ, et al. (2011) Adiponectin level as a consequence of genetic variation, but not leptin level or leptin: adiponectin ratio, is a risk factor for carotid intima-media thickness. Stroke 42 : 1510-1514.

27. Atabek ME, Kurtoglu S, Demir F, Baykara M (2004) Relation of serum leptin and insulin- like growth factor-1 levels to intima-media thickness and functions of common carotid artery in children and adolescents with type 1 diabetes. Acta Paediatr 93: 1052-1057.

28. Kotani K, Sakane N, Saiga K, Kurozawa Y (2005) Leptin : adiponectin ratio as an atherosclerotic index in patients with type 2 diabetes : relationship of the index to carotid intima-media thickness. Diabetologia 48: 2684-2686.

29. Yamazaki Y, Emoto M, Morioka T, Kawano N, Lee E, et al. (2013) Clinical impact of the leptin to soluble leptin receptor ratio on subclinical carotid atherosclerosis in patients with type 2 diabetes. J Atheroscler Thromb 20: 186-194.

30. Scuteri A, Orru M, Morrell C, Piras MG, Taub D, et al. (2011) Independent and additive effects of cytokine patterns and the metabolic syndrome on arterial aging in the SardiNIA Study. Atherosclerosis 215: 459-464.

31. Windham BG, Griswold ME, Farasat SM, Ling SM, Carlson O, et al. (2010) Influence of leptin, adiponectin, and resistin on the association between abdominal adiposity and arterial stiffness. Am J Hypertens 23: 501-507.

32. Vlachopoulos C, Manesis E, Baou K, Papatheodoridis G, Koskinas J, et al. (2010) Increased arterial stiffness and impaired endothelial function in nonalcoholic Fatty liver disease: a pilot study. Am J Hypertens 23: 1183-1189.

33. Satoh N, Naruse M, Usui T, Tagami T, Suganami T, et al. (2004) Leptin-toadiponectin ratio as a potential atherogenic index in obese type 2 diabetic patients. Diabetes Care 27: 2488-2490.

34. Schutte R, Huisman HW, Schutte AE, Malan NT (2005) Leptin is independently 26 associated with systolic blood pressure, pulse pressure and arterial compliance inhypertensive African women with increased adiposity: the POWIRS study. J Hum Hypertens 19: 535-541.

35. Singhal A, Farooqi IS, Cole TJ, O'Rahilly S, Fewtrell M, et al. (2002) Influence of leptin on arterial distensibility: a novel link between obesity and cardiovascular disease? Circulation 106: 1919-1924.

36. Emoto M, Nishizawa Y, Kawagishi T, Maekawa K, Hiura Y, et al. (1998) Stiffness indexes beta of the common carotid and femoral arteries are associated with insulin resistance in NIDDM. Diabetes Care 21: 1178-1182.

37. Kimoto E, Shoji T, Shinohara K, Hatsuda S, Mori K, et al. (2006) Regional arterial stiffness in patients with type 2 diabetes and chronic kidney disease. $J$ Am Soc Nephrol 17: 2245-2252.

38. Lee E, Emoto M, Teramura M, Tsuchikura S, Ueno H, et al. (2009) The combination of IMT and stiffness parameter beta is highly associated with concurrent coronary artery disease in type 2 diabetes. J Atheroscler Thromb 16: 33-39.

39. Kimoto E, Shoji T, Shinohara K, Inaba M, Okuno Y, et al. (2003) Preferential stiffening of central over peripheral arteries in type 2 diabetes. Diabetes 52 : 448-452.

40. Schram MT, Henry RM, van Dijk RA, Kostense PJ, Dekker JM, et al. (2004) Increased central artery stiffness in impaired glucose metabolism and type 2 diabetes: the Hoorn Study. Hypertension 43: 176-181.
41. Henry RM, Kostense PJ, Spijkerman AM, Dekker JM, Nijpels G, et al. (2003) Arterial stiffness increases with deteriorating glucose tolerance status: the Hoorn Study. Circulation 107: 2089-2095.

42. Salomaa V, Riley W, Kark JD, Nardo C, Folsom AR (1995) Non-insulindependent diabetes mellitus and fasting glucose and insulin concentrations are associated with arterial stiffness indexes. The ARIC Study. Atherosclerosis Risk in Communities Study. Circulation 91: 1432-1443.

43. American Diabetes Association (2014) Standards of medical care in diabetes--2014. Diabetes Care 37 Suppl 1: S14-80.

44. Morioka T, Emoto M, Yamazaki Y, Kawano N, Imamura S, et al. (2014) Leptin is associated with vascular endothelial function in overweight patients with type 2 diabetes. Cardiovasc Diabetol 13: 10

45. Yokoyama H, Emoto M, Fujiwara S, Motoyama K, Morioka T, et al. (2004) Short-term aerobic exercise improves arterial stiffness in type 2 diabetes. Diabetes Res Clin Pract 65: 85-93.

46. Tsuchikura S, Shoji T, Kimoto E, Shinohara K, Hatsuda S, et al. (2010) Brachial-ankle pulse wave velocity as an index of central arterial stiffness. Atheroscler Thromb 17: 658-665.

47. Considine RV, Sinha MK, Heiman ML, Kriauciunas A, Stephens TW, et al. (1996) Serum immunoreactive-leptin concentrations in normal-weight and obese humans. N Engl J Med 334: 292-295.

48. Mark AL, Correia ML, Rahmouni K, Haynes WG (2002) Selective leptin resistance: a new concept in leptin physiology with cardiovascular implications. J Hypertens 20: 1245- 1250.

49. Ferreira I, Twisk JW, van Mechelen W, Kemper HC, Seidell JC, et al. (2004) Current and adolescent body fatness and fat distribution: relationships with carotid intima-media thickness and large artery stiffness at the age of 36 years. J Hypertens 22: 145-155.

50. Diamant M, Lamb HJ, van de Ree MA, Endert EL, Groeneveld Y, et al (2005) The association between abdominal visceral fat and carotid stiffness is mediated by circulating inflammatory markers in uncomplicated type 2 diabetes. J Clin Endocrinol Metab 90: 1495-1501.

51. Konishi K, Nakano S, Seto H, Tsuda S, Koya D (2009) Carotid atherosclerosis mediated by visceral adiposity and adipocytokines in type 2 diabetic subjects. Diabetes Res Clin Pract 85: 171-178.

52. Stehouwer CD, Henry RM, Ferreira I (2008) Arterial stiffness in diabetes and themetabolic syndrome: a pathway to cardiovascular disease. Diabetologia 51 : 527-539.

53. Araki T, Emoto M, Yokoyama H, Maeno T, Hatsuda S, et al. (2006) The association of plasma adiponectin level with carotid arterial stiffness. Metabolism 55: 587-592.

54. Scuteri A, Najjar SS, Muller DC, Andres R, Hougaku H, et al. (2004) Metabolic syndrome amplifies the age-associated increases in vascular thickness and stiffness. J Am Coll Cardiol 43: 1388-1395.

55. van Sloten TT, Schram MT, van den Hurk K, Dekker JM, Nijpels G, et al. (2014) Local stiffness of the carotid and femoral artery is associated with inciden cardiovascular events and all-cause mortality: the Hoorn study. J Am Coll Cardiol 63: 1739-1747.

56. Paini A, Boutouyrie P, Calvet D, Tropeano Al, Laloux B, et al. (2006) Carotid and aortic stiffness: determinants of discrepancies. Hypertension 47: 371-376.

57. Dengo AL, Dennis EA, Orr JS, Marinik EL, Ehrlich E, et al. (2010) Arteria destiffening with weight loss in overweight and obese middle-aged and older adults. Hypertension 55: 855-861.

58. Reseland JE, Anderssen SA, Solvoll K, Hjermann I, Urdal P, et al. (2001) Effect of long- term changes in diet and exercise on plasma leptin concentrations. Am J Clin Nutr 73: 240-245. 